\title{
El Niño: ocorrência e duração dos veranicos do Estado de Minas Gerais ${ }^{1}$
}

\author{
Rosandro B. Minuzzi ${ }^{2}$, Gilberto C. Sediyama ${ }^{2}$, Aristides Ribeiro ${ }^{2}$ \& José M. N. da Costa ${ }^{2}$
}

\author{
1 Parte da Dissertação de Mestrado do primeiro autor \\ 2 DEA/UFV. CEP 36570-000, Viçosa, MG. Fone: (31) 3899-1900; E-mail: megadetheoro@bol.com.br (Foto), \\ g.sediyama@ufv.br, ribeiro@ufv.br,.jmcosta@ufv.br
}

Protocolo 148 - 25/9/2003 - Aprovado em 20/1/2005

\begin{abstract}
Resumo: Com o objetivo de caracterizar o início do período chuvoso (IPC), a quantidade de chuvas durante o período chuvoso (PC) e a ocorrência e duração dos veranicos em anos de ocorrência da fase quente do fenômeno climático El Niño-Oscilação Sul (ENOS), analisaram-se dados de precipitação pluvial de 123 localidades do Estado de Minas Gerais e as relações entre a duração dos períodos chuvosos (DPC) e/ou os IPCs com os veranicos de duração de três a seis dias (A) e de sete a dez dias (B), e os IPCs com os totais pluviométricos durante os PCs com os veranicos de classes $\mathrm{A}$ e $\mathrm{B}$, respectivamente. Os resultados indicaram uma característica marcante do El Niño em ocasionar chuvas abaixo da média no nordeste do Estado e chuvas acima da média climática no sudoeste de Minas Gerais. As estiagens ao norte e nordeste do Estado corresponderam a períodos superiores a 15 dias e as chuvas acima da média, no sudoeste, foram melhor correlacionadas com os veranicos de duração de três a seis dias.
\end{abstract}

Palavras-chave: precipitação, período chuvoso, oceano Pacífico

\section{El Niño: Occurrence and duration of dry spells in the State of Minas Gerais - Brazil}

\begin{abstract}
Daily precipitation data from 123 locations of the State of Minas Gerais were analyzed to characterize the beginning of the rainy season (IPC), the amount of rainfall during the rainy season (PC) and the occurrence and length of the dry spell in years associated to El Niño Southern Oscillation (ENSO). The relationship between the duration of rainy season (DPC), begining of the rainy period and the dry spells from three to six days $(A)$; from seven to ten days $(B)$ and the IPC with the rainfall during the rainy periods with dry spells $(A)$ and $(B)$ were also studied. The results showed that ENSO is related to rainfall below historical average in the northeastern region of the State of Minas Gerais, and to rainfalls above the climatic average in the southwestern region. The duration of the dry spells in the northern and northeastern region of the state were higher than 15 days, and the rainfall above normal in the southwestern part of the state were better correlated to dry spells of three to six days.
\end{abstract}

Key words: precipitation, rainy season, Pacific ocean

\section{INTRODUÇÃO}

Assuntos referentes à água doce, que contribui com 2,5\% do total de água existente no Planeta, sempre estão em destaque na mídia, seja para denunciar sua escassez, sua contaminação ou os conflitos pelo uso, mostrando que a disponibilidade hídrica diminui gradativamente, devido ao crescimento populacional e à degradação do meio ambiente. Portanto, em áreas urbanas ou rurais, o conhecimento da distribuição espaço-temporal das chuvas é indispensável para melhor gerenciamento dos recursos hídricos durante os períodos secos, e para as tomadas de decisão pertinentes à defesa civil, durante eventos de chuvas excessivas. Neste contexto, maior importância deve ser dada às estiagens e às chuvas em excesso, associadas aos fenômenos de grande escala, como o El Niño-Oscilação Sul (ENOS), que afeta a circulação geral da atmosfera.

Com grande extensão territorial e abrangendo muitas riquezas hidrológicas, o Estado de Minas Gerais, localizado na região Sudeste do Brasil, possui vegetação e relevo bem diversificados, e extensa variabilidade na distribuição das chuvas, apresentando dois períodos marcantes: um seco, no inverno, e outro 
chuvoso, no verão, sendo que, neste último, ocorrem de 80 a $90 \%$ do total anual de chuvas, induzindo a atividades agrícolas mais intensas, em especial as culturas de sequeiro (Paiva, 1997).

No entanto, em Minas Gerais e como em toda a zona intertropical, ocorrem períodos de interrupção da precipitação, durante o período chuvoso (PC). Este fenômeno é denominado, veranico, que adquire significativa importância econômica, uma vez que a sua ocorrência freqüente pode reduzir a produtividade das culturas (Luchiari et al., 1986), principalmente quando as disponibilidades de água do solo são inadequadas ou insuficientes para atender à demanda evaporativa dos campos cultivados (Oladipo, 1985). A definição de veranico para as regiões tropicais é muito divergente, a começar pelo que se considera como um dia seco. Chatfield (1966) recomenda o valor de $1 \mathrm{~mm}$ de chuva diária, abaixo do qual se considera como dia seco. Castro Neto \& Vilella (1986) consideram veranico os períodos de precipitação pluvial inferior a $3 \mathrm{~mm}$, outros, sendo inferior a $1 \mathrm{~mm}$ (Assad \& Sano, 1998), ou havendo precipitação inferior a $5 \mathrm{~mm}$, num período de sete dias (Silva et al., 1981).

A literatura (Quadros, 1993; Fedorova et al., 2000; Grimm et al., 1998; Silva, 2000) cita estudos referentes a variações no número de ocorrências e de deslocamentos de sistemas meteorológicos, tais como a Zona de Convergência do Atlântico Sul (ZCAS), a Alta da Bolívia, zonas frontais, Vórtice Ciclônico de Ar Superior e outros, associados aos anos de ocorrência do ENOS, que é um dos principais mecanismos responsáveis pela variabilidade das precipitações pluviais, durante o PC em Minas Gerais. Fedorova et al. (2000), estudaram o comportamento de sistemas frontais no período de julho/1997 a março/1998 (representando ano de El Niño-EN), julho/1998 a março/1999 (representando ano de La Niña-LN) e julho/1996 a março/1997 (representando um ano neutro em relação aos fenômenos climáticos). Para a região Sudeste, os autores destacam que nos meses em que os fenômenos LN e EN estavam na fase mais ativa, a quantidade de dias com frentes frias na faixa de latitudes entre 20 e $40^{\circ} \mathrm{S}$ no ano EN atingiu 90,3\% dos dias analisados e no ano LN diminui até 56,7\%. Quadros (1993) comparou dois casos extremos de ZCAS e sugeriu que, durante um evento EN, a ZCAS apresenta-se inibida ou tende a formar-se fora de sua região preferencial de ocorrência (aproximadamente ao norte de $25^{0} \mathrm{~S}$ sobre a costa leste do continente sul-americano).

Os impactos do ENOS no Brasil são mais estudados e marcantes nas regiões Sul e Nordeste e, mesmo assim, principalmente no Nordeste, os resultados em dadas situações de atuação dos fenômenos são incompatíveis, conforme indicado por Kane (2001), que analisando os 52 eventos EN ocorridos entre 1871 e 1998, 31 estiveram associados à seca e 21 não. $\mathrm{O}$ autor sugere que essas exceções estão associadas sobretudo às condições do oceano Atlântico. Na região Sul, Carmona \& Berlato (2002) avaliaram os efeitos associados ao EN e LN sobre o rendimento e nos elementos meteorológicos mais importantes para a cultura do arroz irrigado no Rio Grande do Sul. O estudo mostra que a menor disponibilidade de insolação que ocorre no período outubro a fevereiro, é uma das causas do evento EN ser desfavorável à cultura do arroz irrigado e, em média, tanto nos anos de eventos LN como nos anos de EN, ocorre menor número de dias com temperaturas mínimas prejudiciais ao arroz nos meses de janeiro e fevereiro, quando comparados com anos neutros; já Fontana \& Berlato (1996) avaliaram a influência do ENOS sobre a precipitação e o rendimento de milho no Rio Grande do Sul e se verificaram desvios positivos em relação à média de precipitação nos meses de setembro e outubro e desvios negativos nos meses de novembro a abril, para as localidades de Passo Fundo e Cruz Alta. Os meses com desvios negativos de precipitação coincidem com os meses mais críticos para as culturas de primavera-verão. É nesta época que as culturas estão em pleno desenvolvimento, coincidindo com elevada demanda evaporativa da atmosfera e, portanto, alto consumo de água.

Na região Sudeste do Brasil, a resposta ao fenômeno ENOS não é tão linear quanto no Cone Sul da América do Sul, talvez porque a região dependa mais do que ocorre sobre o Atlântico, e a resposta no Atlântico não é tão simétrica quanto no Pacífico. A pouca consistência das anomalias no Sudeste é devida justamente ao caráter de transição da região, pois as anomalias podem deslocar-se para norte ou para sul de um evento para outro podendo, assim, alterar o seu sinal em relação a eventos anteriores (Grimm \& Ferraz, 1998). Talvez por esta razão o estudo sobre a influência espaço-temporal do ENOS nos elementos climáticos seja mais carente no Sudeste do País, quando comparado com as regiões Sul e Nordeste, em particular se baseando em uma análise detalhada, com ampla base de dados.

Com o exposto, conduziu-se este trabalho com o objetivo de analisar a influência do fenômeno El Niño no período chuvoso, a freqüência de ocorrência e a duração de veranicos para o Estado de Minas Gerais, identificando-se regiões homogêneas.

\section{MATERIAL E MÉTODOS}

No trabalho, utilizaram-se dados de 123 estações pluviométricas (Figura 1), pertencentes à Agência Nacional de Águas (ANA), situadas no Estado de Minas Gerais, entre os paralelos $14^{0} 13^{\prime}$ e $22^{\circ} 55^{\prime}$ de latitude Sul e entre os meridianos $39^{\circ} 51^{\prime}$ e $51^{\circ} 02^{\prime}$ de longitude Oeste. A fim de evitar viés no processo de interpolação dos dados, foram incluídas 11 estações, também pertencentes à ANA, e localizadas a uma distância máxima de $50 \mathrm{~km}$ dos limites de Minas Gerais. Cada uma das 123 estações foi considerada homogênea após a realização do teste de seqüência, além de atenderem ao número mínimo de sete ocorrências do El Niño (EN).

Para o emprego da cronologia e intensidade do EN, consideraram-se os eventos com forte e moderada intensidade entre os anos de 1936 a 2000, se considerando a influência durante os meses de ocorrência do período chuvoso (PC), ou seja, final de um ano e início do outro (Tabela 1). Para tais classificações, foram utilizados os valores da temperatura da superfície do mar (TSM) da região do Niño 3.4 e do índice de oscilação Sul (IOS), fornecidos pela base de dados do "International Research Institute for Climate Prediction (IRI)" tendo como indicador de anomalias negativas o IOS $\geq-0,5$. Os anos em que ocorreram eventos de fraca intensidade foram considerados anos neutros (AN), visto que as oscilações da TSM e do IOS no Pacífico equatorial pouco diferiram das 


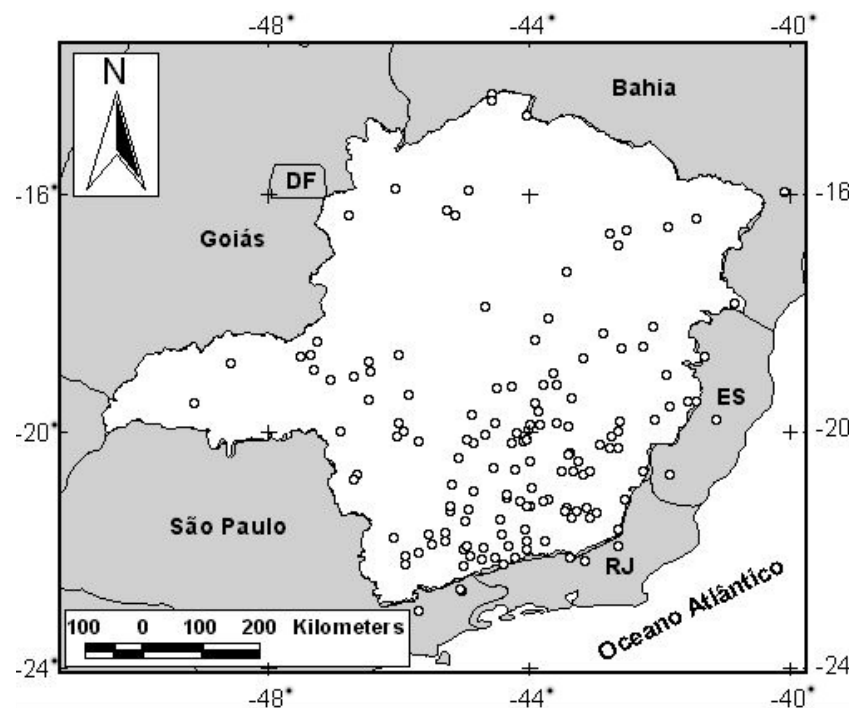

Figura 1. Localização geográfica das estações pluviométricas utilizadas no presente estudo, situadas no Estado de Minas Gerais, e também nas regiões limítrofes dos Estados de São Paulo, Rio de Janeiro, Espírito Santo e Bahia

Tabela 1. Cronologia das ocorrências e respectivas intensidades do El Niño

\begin{tabular}{cl} 
Ano (Período El Niño) & Intensidade El Niño \\
\hline $1939-1940$ & Moderado \\
$1940-1941$ & Forte \\
$1941-1942$ & Moderado \\
$1946-1947$ & Moderado \\
1951 & Moderado \\
$1957-1958$ & Forte \\
$1965-1966$ & Moderado \\
$1969-1970$ & Moderado \\
$1972-1973$ & Forte \\
$1977-1978$ & Moderado \\
$1982-1983$ & Forte \\
$1986-1987$ & Forte \\
1987 & Forte \\
$1991-1992$ & Forte \\
$1992-1993$ & Moderado \\
$1994-1995$ & Moderado \\
$1997-1998$ & Forte \\
\hline
\end{tabular}

condições normais da região, além dos eventos considerados como La Niña não constarem desse estudo.

As datas inicial e final do período chuvoso (IPC e FPC, respectivamente) foram determinadas conforme o critério descrito a seguir. O IPC foi definido como o dia, após uma data específica ( $\left(1^{\circ}\right.$ de setembro), que tem a primeira ocorrência de uma quantidade mínima de $20 \mathrm{~mm}$ de chuva totalizada em até dois dias consecutivos, desde que ocorra pelo menos um dia de chuva em cada período de 15 dias, durante os próximos 45 dias. Considerou-se dia chuvoso aquele em que ocorreu precipitação igual ou superior a $1 \mathrm{~mm}$. O FPC foi considerado como primeiro dia de um período seco com, pelo menos, 15 dias de duração, que terminasse após 15 de março, podendo ocorrer antes desta data, desde que a seqüência de, pelo menos, 15 dias secos, termine depois do dia 15 de março.
As médias obtidas para o IPC, na série referente aos anos de ocorrência do fenômeno ENOS, foram classificadas de acordo com (Tabela 2), em decorrência das peculiaridades da região em estudo.

Tabela 2. Classificação do início do período chuvoso, tendo como referência a data média dos anos neutros. Adaptado de Paiva (1997)

\begin{tabular}{ccc}
\hline C & \multicolumn{1}{c}{ Descrição } \\
\hline I & MP & de 30 a 20 dias anteriores à data média do IPC dos AN \\
II & P & a partir de 10 dias anteriores à data média do IPC dos AN \\
III & N & 10 dias antes e 10 dias após a data média do IPC dos AN \\
IV & T & a partir de 10 dias posteriores à data média do IPC dos AN \\
V & MT & de 20 a 30 dias posteriores à data média do IPC dos AN \\
\hline MP - muito precoce; P - precoce; N - Normal; T - Tardia; MT - Muito Tardia
\end{tabular}

Além das médias foram também obtidos os valores extremos do IPC, pois a 'normal' não deve ser representada apenas em termos de sua média, considerando-se que cada valor médio calculado deve ser acompanhado de informações sobre outras medidas de dispersão. Assim, o mesmo critério utilizado na Tabela 2 foi, também, empregado para realizar novas classificações do IPC, porém baseados nos valores extremos máximo ou mínimo. Para cada classificação obtida para o IPC; baseado nos valores médio, extremos máximo ou mínimo, atribuiu-se um fator de ponderação, conforme apresentado na Tabela 3, de forma que, para os IPCs extremos, ponderou-se por um valor menor do que em relação ao valor do IPC médio obtido.

Tabela 3. Fatores de ponderação de acordo com a classificação obtida do IPC, baseados nos valores médio, máximo e mínimo

\begin{tabular}{lcc} 
& \multicolumn{2}{c}{ Fatores de ponderação* } \\
\cline { 2 - 3 } \multicolumn{1}{c}{ Classificação } & VM do IPC & $\begin{array}{c}\text { VE do IPC } \\
\text { (máximo ou mínimo) }\end{array}$ \\
\hline Normal & 4 & 3 \\
Precoce/Tardia & 3 & 2 \\
Muito precoce/Muito tardia & 2 & 1 \\
\hline IPC - Data inicial do periodo chuvoso; VM - Valor Médio; VE - Valor Extremo; EN - El Niño
\end{tabular}

Portanto, a soma dos três valores como fator de ponderação, representa o percentual de ocorrência que uma estação tem do IPC não ser afetado pelo fenômeno EN, sendo o valor máximo possível 10 e o mínimo 4 , ou seja, 100 ou $40 \%$, respectivamente, de que o IPC não seja influenciado pelo El Niño. Por exemplo, o IPC de uma estação foi classificado como 'normal' baseado nos valores médio (4) e mínimo (3) de sua série, e como 'muito precoce' com base no valor máximo (1); assim, haverá $80 \%$ (4+ $3+1)$ de chance do IPC não sofrer influência.

Quanto ao total pluviométrico, durante o período chuvoso, as análises foram moldadas na distribuição dos desvios padrão normalizados (D), dada pela Eq. 1:

$$
\mathrm{D}=\frac{(\mathrm{x}-\overline{\mathrm{u}})}{\sqrt{\frac{\mathrm{s}}{\mathrm{n}_{\mathrm{x}}}+\frac{1}{\mathrm{n}_{\mathrm{u}}}}} * 100 \%
$$


em que $\mathrm{x}$ é igual ao valor médio da série em estudo (ENOS), $\overline{\mathrm{u}}$ o valor médio da série de referência $(\mathrm{AN}), \mathrm{n}_{\mathrm{x}}$ o número de dados da série em estudo (ENOS), $\mathrm{n}_{\mathrm{u}}$ o número de dados da série de referência $(\mathrm{AN})$ e s o desvio padrão ponderado. Os PCs receberam as seguintes classificações, conforme Alves \& Repelli (1992): muito chuvoso: $\mathrm{D} \geq 40 \%$; chuvoso: $15 \%<\mathrm{D}<$ 40\% ; normal: $-15 \% \leq \mathrm{D} \leq 15 \%$; seco: $-40 \% \leq \mathrm{D}<-15 \%$ e muito seco: $\mathrm{D}<-40 \%$.

Para o cálculo das anomalias de precipitação escolheramse estações pluviométricas com maior número de PCs a fim de cada uma representar as regiões climaticamente homogêneas em Minas Gerais, de acordo com a análise de Aspiazu et al. (1990) (Figura 2). Os PCs ausentes nas séries de quatro estações foram descartados; assim, os períodos utilizados são apresentados na Tabela 4, de acordo com as respectivas classes.

A definição de um período de veranico varia de acordo com os objetivos propostos. Por exemplo, se for considerado de acordo com o déficit hídrico numa cultura, isto vai depender de vários fatores, como o tipo e o manejo de solo da área cultivada, a profundidade e densidade do sistema radicular da cultura, a população de plantas, dentre outros fatores fisiológicos. Neste trabalho fez-se uma junção dos critérios utilizados por Castro \& Vilella (1986) e Assad \& Sano (1998) considerando-se, como veranico, o período de pelo menos três dias secos consecutivos; desta forma, foram determinadas as freqüências médias da ocorrência de veranicos para as classes, com os seguintes intervalos de duração, em cada uma das séries: três a seis dias (A); sete a dez dias (B); 11 a 14 dias (C) e acima de 15 $\operatorname{dias}(\mathrm{D})$.

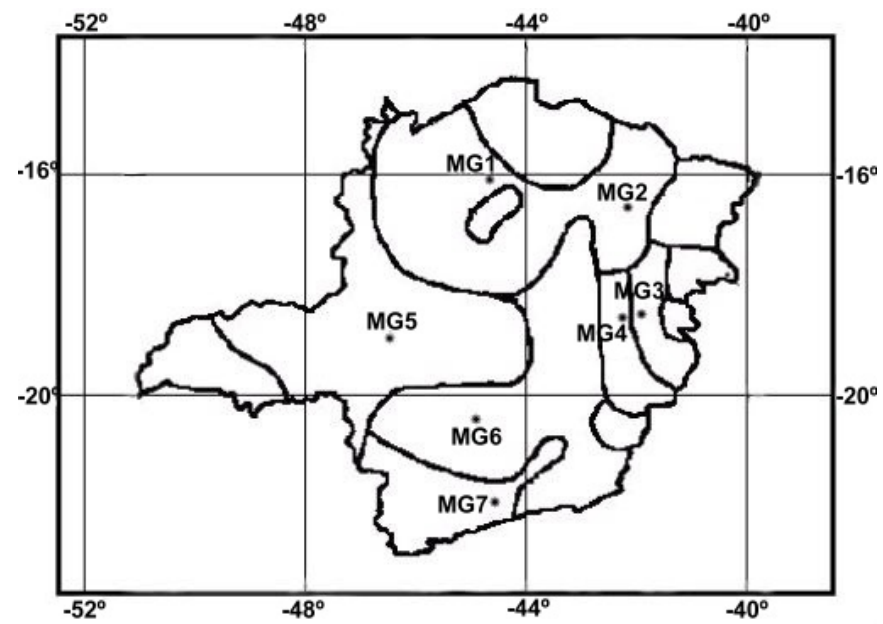

Figura 2. Localização das sete estações selecionadas e delimitadas pelas regiões climaticamente homogêneas definidas por Aspiazu et al. (1990)
As relações entre o IPC com os veranicos de classes A e B foram obtidas por meio da análise de regressão linear simples, baseada nos valores das estações destacadas na Tabela 4 não se considerando, entretanto, a igualdade dos PCs. O mesmo procedimento foi adotado para a duração dos períodos chuvosos. A técnica da regressão linear múltipla foi utilizada para avaliar a relação entre o IPC e o total pluviométrico do PC (variáveis independentes) com os veranicos de classes A e/ou $\mathrm{B}$ (variáveis dependentes).

Os valores obtidos nas análises foram geoespacializados, utilizando-se o software de SIG (ArcView GIS 3.2). Utilizou-se o interpolador linear IDW do software, em que o peso da célula a ser interpolada é dado por uma média ponderada que utiliza o peso dos pontos de controle mais próximos (definido pelo usuário), ponderados pelo inverso da distância, elevado a um expoente $\mathrm{m}$ (definido pelo usuário). Foram considerados os 12 pontos mais próximos para interpolação e o emprego da terceira potência para o cálculo da distância euclidiana, salvo exceções com o objetivo de corrigir falhas, em algumas interpolações.

\section{RESULTADOS E DISCUSSÃO}

A Figura 3A ilustra a influência do El Niño (EN) com base no valor médio do IPC em que, basicamente, as regiões do extremo norte, uma pequena área do Nordeste e o centro do Estado, estão sob influência do fenômeno. A pequena área classificada como 'muito tardia' é resultante dos valores obtidos por apenas uma estação que, mesmo não possuindo muitos dados (sete EN e 20 anos neutros) está situada a uma altitude de $1200 \mathrm{~m}$, fator a ser considerado. A soma dos três valores como fator de ponderação, baseados no valor médio, máximo e mínimo, fornecem maior precisão quanto a tendência do El Niño em não influenciar o IPC nas regiões da metade Sudoeste de Minas Gerais. Na Figura 3B observa-se que, na citada região do Estado, há percentuais acima de $80 \%$, ou seja, as chances do fenômeno climático não alterar o IPC, são grandes; em contrapartida, as áreas atingidas (destacadas na Figura 3A) foram as que obtiveram menores percentuais; como exemplo, no extremo norte do Estado, representado pela estação de Manga, na qual foi obtido o menor percentual (50\%).

A influência do El Niño na precipitação durante o PC é apresentada na Figura 4. Destaca-se a relativa semelhança de áreas atingidas pela seca, como no norte do Estado, centro e sul do Jequitinhonha, noroeste e sudoeste do Vale do Rio Doce, centro da Zona da Mata e Região Metropolitana de Belo Horizonte (RMBH) e de áreas com tendência de chuvas acima da média, como no leste do Triângulo Mineiro e Alto Paranaíba

Tabela 4. Coordenadas geográficas das sete estações pluviométricas selecionadas e os períodos chuvosos utilizados nas séries

\begin{tabular}{lcccccc}
\hline \multicolumn{1}{c}{ Municípios } & Região & Lat. $\left({ }^{\circ}\right)$ & Log. $\left({ }^{\circ}\right)$ & Alt. $(\mathrm{m})$ & Anos neutros & El Niño \\
\hline São Francisco & MG1 & $-15,95$ & $-44,87$ & 448 & $1948 / 49,1952 / 53,1953 / 54,1956 / 57$, & $1946 / 47,1951 / 52$, \\
Coronel Murta & MG2 & $-16,61$ & $-42,19$ & 279 & $1958 / 59,1959 / 60,1960 / 61,1961 / 62$, & $1957 / 58,1965 / 66$, \\
Campanário & MG3 & $-18,24$ & $-41,75$ & 240 & $1962 / 63,1963 / 64,1967 / 68,1968 / 69$, & $1969 / 70,1972 / 73$, \\
Coroaci & MG4 & $-18,61$ & $-42,28$ & 530 & $1971 / 72,1974 / 75,1976 / 77,1978 / 79$, & $1977 / 78,1982 / 83$, \\
Carmo do Paranaíba & MG5 & $-19,01$ & $-46,51$ & 1067 & $1979 / 80,1980 / 81,1981 / 82,1983 / 84$, & $1986 / 87,1987 / 88$, \\
Lamounier & MG6 & $-20,47$ & $-45,04$ & 738 & $1984 / 85,1985 / 86,1990 / 91,1993 / 94$, & $1991 / 92,1992 / 93$, \\
Aiuruoca & MG7 & $-21,98$ & $-44,60$ & 966 & $1995 / 96,1996 / 97$. & $1994 / 95,1997 / 98$. \\
\hline
\end{tabular}


A.

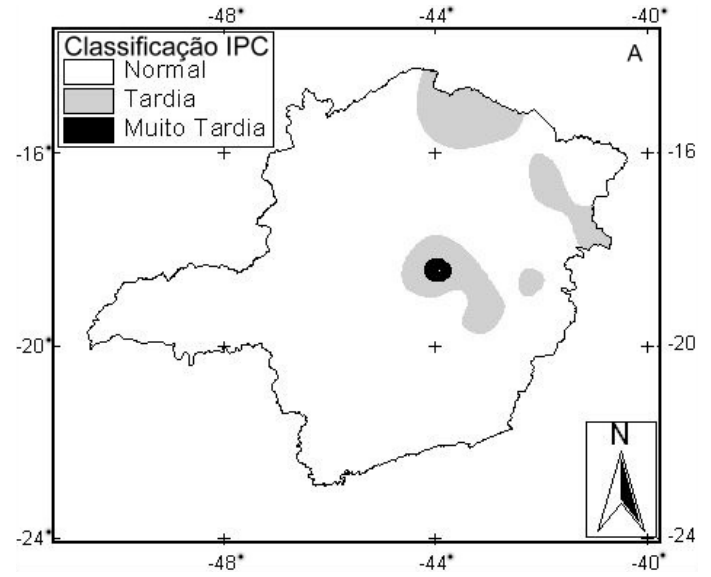

B.

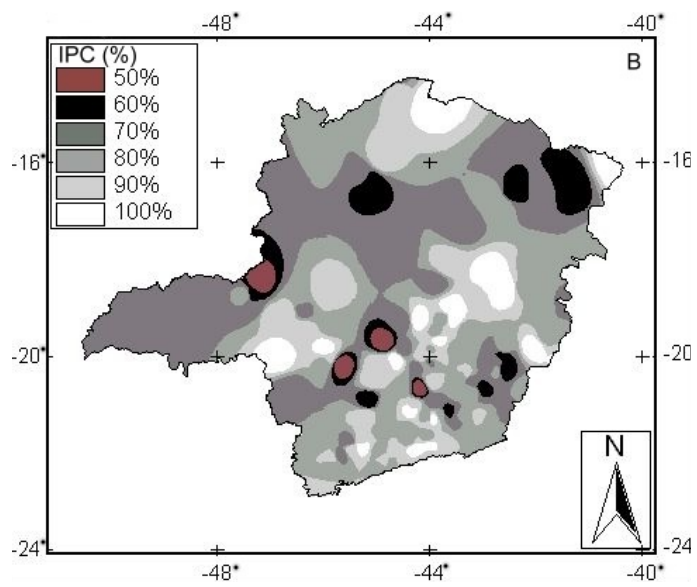

Figura 3. Classificação do inicio do periodo chuvoso (IPC) baseado na média (A) e os percentuais moldados nos valores de ponderação referentes às chances dos IPCs serem influenciados pelo ENOS (B)

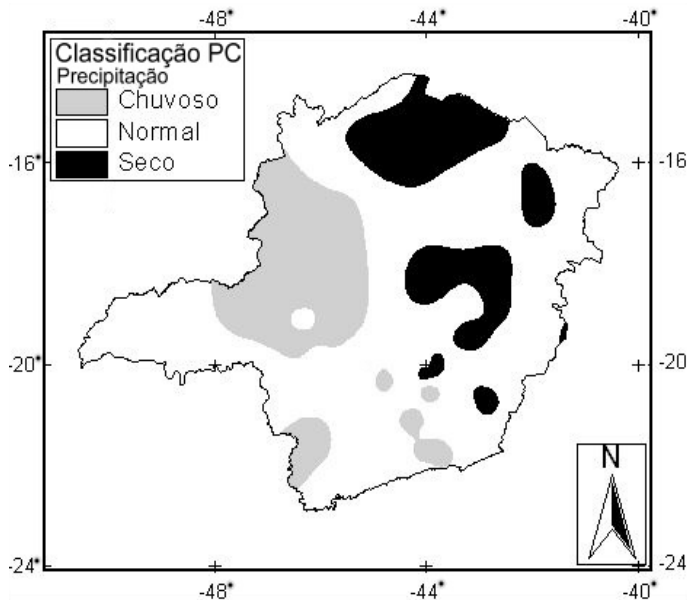

Figura 4. Mapa temático referente à influência do fenômeno El Niño na precipitação total, durante o período chuvoso

(TMAP), noroeste e sudoeste do Estado, região central do Campo das Vertentes e sul da RMBH e Zona da Mata. Ressaltase que nos episódios El Niño a área mais chuvosa abrangendo grande parte da região noroeste de Minas Gerais é escassa, em termos de dados pluviométricos, classificação esta resultante de apenas uma estação, conforme se observa na distribuição das estações pluviométricas (Figura 1). O mesmo argumento é válido para esclarecer a grande área mais seca no Norte do Estado, classificação esta resultante de apenas duas estações, porém neste caso há maior credibilidade pelo fato de que em uma dessas estações, a de São Francisco, se dispõe de grande número de PCs incluídos no estudo (16 El Niño e 24 anos neutros). As áreas chuvosas localizadas ao sul da RMBH e a leste da região centro-oeste, bem como a área seca no centro da Zona da Mata, foram classificadas levando-se em conta os valores de apenas uma estação; então, a discussão não adentra no número de PCs utilizados, pois estes são equivalentes à de estações próximas, ou seja, se o motivo para tais classificações se restringisse ao número de dados, as estações próximas também deveriam ser influenciadas, resultando nas citadas classificações.

A pequena região localizada no meio da área classificada como chuvosa no TMAP, é resultante dos valores de uma estação localizada a 1067 m de altitude, valor alto comparativamente àqueles das estações mais próximas. Situação semelhante ocorre em ambos os fenômenos na área seca próximo à capital mineira. Os resultados advindos desta área são de estações localizadas na serra do Curral, orientada no sentido noroeste-sudeste e que, mesmo sendo de pequena extensão, possui grande elevação.

Generalizando, observa-se uma divisão nas influências, ou seja, na metade sudoeste, onde há somente regiões com tendência de chuvas acima da média climática e, na metade nordeste, apenas regiões com tendência oposta, estando ambas as regiões associadas às características marcantes das regiões Sul e Nordeste do Brasil, durante os eventos El Niño, respectivamente, bem como o sentido desta linha divisória e imaginária ser o mesmo do posicionamento das ZCAS e das frentes frias, quando de sua passagem pelo Estado. Como exemplo, na região Sul do País, mais especificamente no Rio Grande do Sul, onde a previsibilidade para o fenômeno é maior, Puchalski (2000) mostrou que, em geral, o El Niño está associado a precipitações pluviais acima da média, sendo a região noroeste do Estado a mais atingida pelo fenômeno.

A Figura 5 confirma a irregularidade nos eventos El Niño, em que se destaca tendência para que as chuvas fiquem abaixo

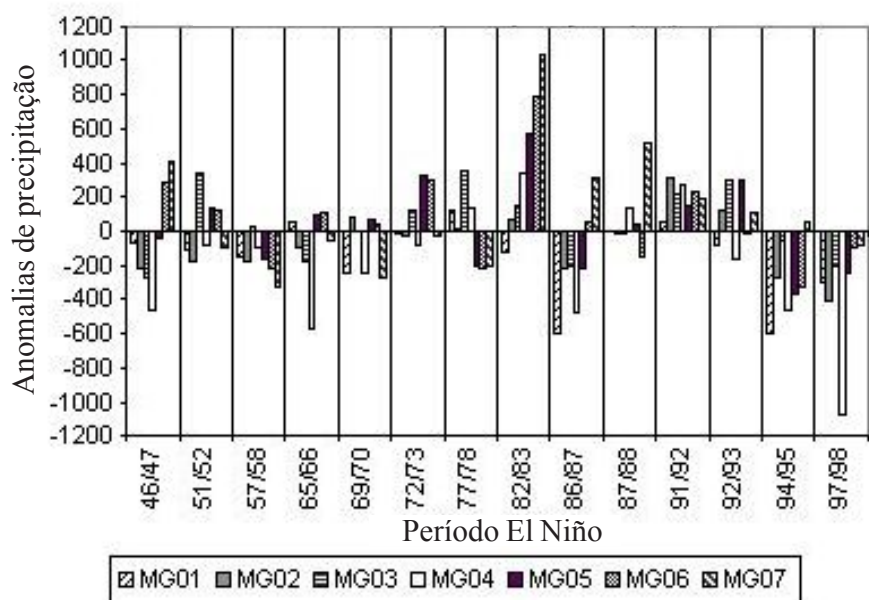

Figura 5. Representação esquemática das anomalias em eventos El Niño 
da média nas estações MG1, MG2 e MG4, que tiveram apenas uma, três e quatro ocorrências de desvio negativo, respectivamente, sendo que o único valor positivo na estação de São Francisco foi de apenas $52,8 \mathrm{~mm}$, enquanto as anomalias negativas mais significativas ocorreram nos eventos de 1986/ 87 e 1994/95. Na estação MG2, sofrendo com estiagens em anos El Niño, o efeito do fenômeno não é muito rigoroso, constatando-se o oposto na região representada pela estação de Coroaci, havendo diferenças somente em relação ao seu desvio padrão superior a $100 \mathrm{~mm}$, principalmente durante o El Niño de 1997/98, que causou anomalias negativas em todas as estações. Nas estações MG3, MG5, MG6 e MG7, há quase uma igualdade nos sinais das anomalias, com leve tendência de chuvas acima da média, notando-se que as anomalias positivas são mais rigorosas que as negativas. Em geral, esses valores ratificam as classificações obtidas apresentadas na Figura 4 pois, com exceção do EN 1994/95, as estações localizadas na metade sudoeste de Minas Gerais (MG5, MG6 e MG7) obtiveram somente valores positivos, sobretudo no evento de 1982/83, justificando o fato de ser considerado um dos mais rigorosos, ocasionando desvios de 573, 789 e $1032 \mathrm{~mm}$, respectivamente. O mesmo adjetivo é válido para o evento de 1997/98 porém, curiosamente, o efeito foi oposto.

Essas diferenças nas anomalias entre eventos, em especial nas estações a nordeste e sudoeste do Estado, assemelham-se aos resultados encontrados por Grimm \& Natori (2002) para a região sudeste da América do sul, ou seja, mesmo com essas diferenças há característica comum de excesso de chuva na
A.

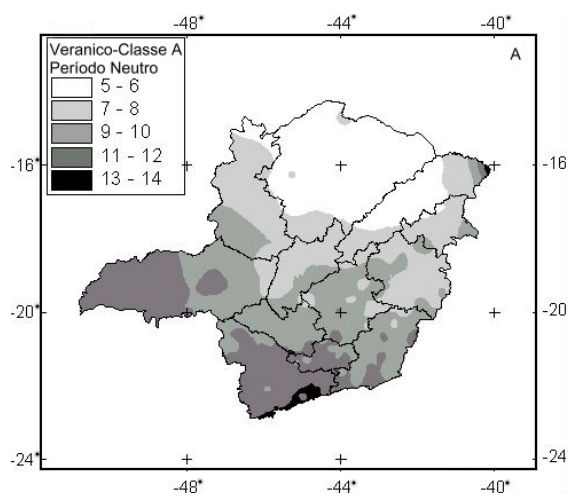

D.
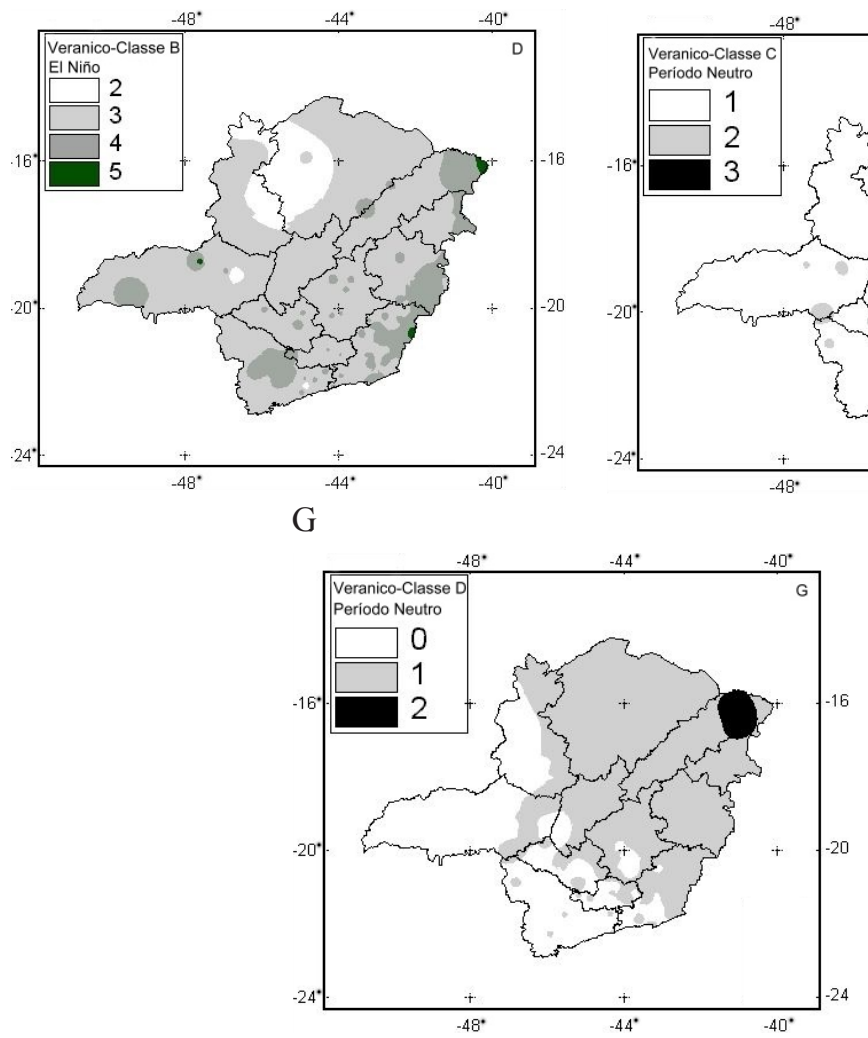

B.

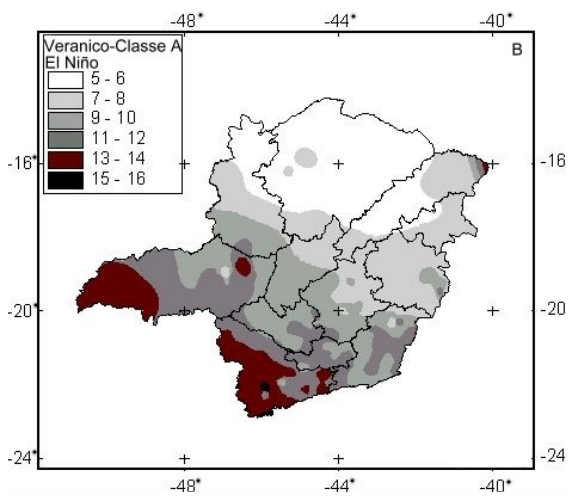

E.

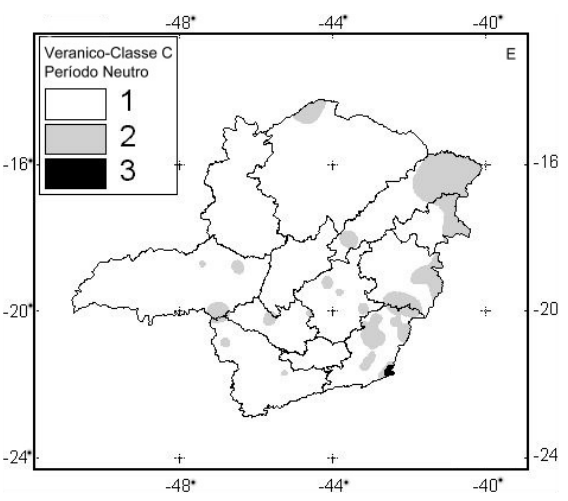

H.
C.

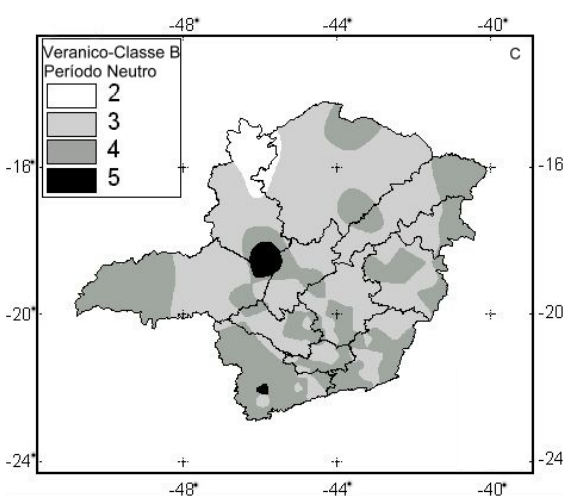

F.

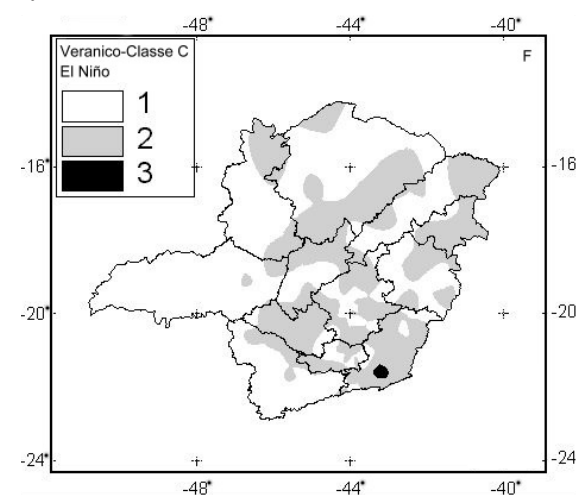

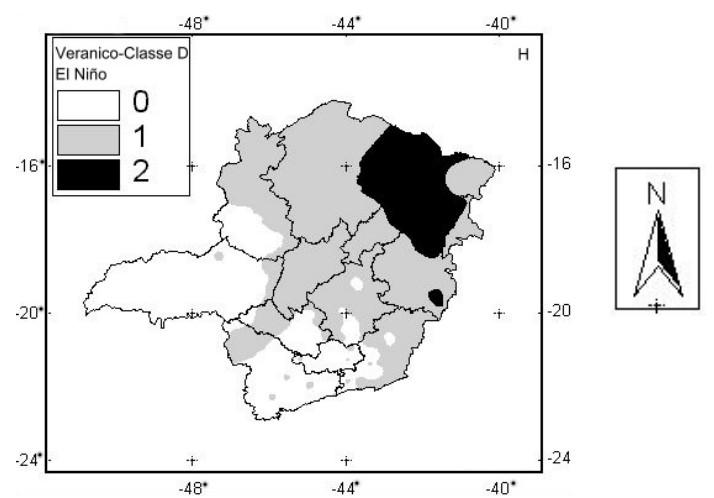

Figura 6. Distribuição espacial no número de ocorrências de veranico com duração de três a seis dias nas séries de anos neutros (A) e de El Niño (B); de veranico com duração de sete a dez dias nas séries de anos neutros (C) e de El Niño (D); de veranico com duração de 11 a 14 dias nas séries de anos neutros (E) e de El Niño (F) e; de veranico com duração superior a 15 dias nas séries de anos neutros $(\mathrm{G})$ e de El Niño $(\mathrm{H})$ 
região sul e deficiência no sudeste e sul da região nordeste do Brasil.

Relacionando-se espacialmente o número médio de ocorrência de veranicos de classe A (Figuras 6A e B), vê-se que as situações mais notáveis são os aumentos nos números de 11 a 12 e de 13 a 14 veranicos no sul-sudoeste do Estado, em anos El Niño, bem como o oeste do TMAP e Zona da Mata Mineira. A Figura 6D em comparação com a Figura 6C, mostra uma situação mais favorável durante eventos El Niño, com significativa redução de quatro ocorrências por PC. Em compensação, ocorre grande aumento no número de ocorrências de veranico com duração de 11 a 14 dias, o que se observa por comparação entre as Figuras 6E e 6F, principalmente nas regiões centro-oeste, Zona da Mata, vale do Mucuri, regiões Metropolitana de Belo Horizonte e Norte do Estado. Nas Figuras 6G e 6H, observa-se o comportamento dos veranicos com duração superior a 15 dias. É notório o aumento de duas ocorrências em anos El Niño, no Nordeste do Estado, sendo esta a diferença mais significativa.

Os coeficientes de correlação ( $r$ ) da Tabela 5, indicam as possíveis relações entre a DPC e o IPC com os veranicos das classes A e B. Nota-se que em anos do ENOS praticamente inexiste uma correlação entre a DPC e os veranicos nas regiões representadas pelas estações MG1, MG2, MG3, MG4 e MG6, ocorrendo o oposto para a estação MG5 em relação aos veranicos com duração de sete a dez dias $(\mathrm{r}=0,78)$ e no sul de Minas Gerais, devido aos valores obtidos pela estação MG7 $(\mathrm{r}=0,74)$ em relação a veranicos da classe A; no entanto, o único coeficiente com sinal negativo na relação com veranicos de classe B, para a estação MG2, significa que, a medida em que a DPC aumenta, o número de veranicos diminui, mesmo que seja em baixa proporção.

Tabela 5. Coeficientes de correlação entre a DPC e o IPC com os veranicos de classes A e B

\begin{tabular}{llllrr}
\hline & \multicolumn{2}{c}{ ENOS $-\mathrm{A}$} & & \multicolumn{2}{c}{ ENOS - B } \\
\cline { 2 - 3 } \cline { 5 - 6 } & DPC & IPC & & DPC & IPC \\
\hline MG1 & 0,53 & $-0,43$ & & 0,66 & $-0,41$ \\
MG2 & 0,59 & $-0,44$ & & $-0,17$ & $-0,16$ \\
MG3 & 0,57 & 0,01 & & 0,67 & $-0,77$ \\
MG4 & 0,02 & 0,67 & & 0,60 & $-0,26$ \\
MG5 & 0,54 & $-0,33$ & & 0,78 & $-0,19$ \\
MG6 & 0,48 & $-0,28$ & & 0,41 & $-0,21$ \\
MG7 & 0,74 & $-0,40$ & & 0,24 & 0,19 \\
\hline
\end{tabular}

Quanto à relação entre IPC e os veranicos citados, ressaltase que o IPC, para as sete estações, não sofreu influência do fenômeno; assim, talvez esteja neste detalhe o fato dos valores não indicarem relação entre as duas variáveis, conforme consta na Tabela 5, salvo a estação MG3, que obteve um coeficiente igual a $-0,77$ na relação com o veranico B e que, de certa forma, foi compensado pelo valor quase nulo para o veranico com duração de três a seis dias, sendo o menor valor obtido no que se refere à correlação. A divergência nesta análise refere-se aos sinais dos coeficientes, em que há predomínio do número de veranicos diminuir sempre que a data do IPC tarda a iniciar.

A Tabela 6 indica as classificações das sete estações referentes ao IPC e precipitação total durante o PC, além dos
Tabela 6. Valores dos coeficientes de correlação linear múltipla (r) envolvendo IPC, precipitação total durante o PC e veranicos das classes A e B

\begin{tabular}{|c|c|c|c|c|}
\hline & \multicolumn{2}{|c|}{ El Niño } & \multirow{2}{*}{$\begin{array}{c}\text { Classe A } \\
\text { r }\end{array}$} & \multirow{2}{*}{$\begin{array}{c}\text { Classe B } \\
\text { r }\end{array}$} \\
\hline & Classificação IPC & $\begin{array}{l}\text { Classificação } \\
\text { precipitação }\end{array}$ & & \\
\hline MG1 & Normal & Seco & 0,48 & 0,49 \\
\hline MG2 & Normal & Normal & 0,44 & 0,16 \\
\hline MG3 & Normal & Normal & 0,21 & 0,76 \\
\hline MG4 & Normal & Seco & 0,81 & 0,12 \\
\hline MG5 & Normal & Normal & 0,64 & 0,30 \\
\hline MG6 & Normal & Normal & 0,31 & 0,21 \\
\hline MG7 & Normal & Normal & 0,40 & 0,19 \\
\hline
\end{tabular}

coeficientes de correlação linear múltipla (r), que indicam uma associação entre essas citadas variáveis com o veranico A na estação MG4 $(\mathrm{r}=0,81)$. Associando este resultado àquele apresentado na Tabela 5 para esta estação, deduz-se que, mesmo o IPC tendo sido classificado como 'normal', este exerce importante contribuição pois, além de ser um dos maiores valores, o sinal indica aumento de veranicos proporcional ao aumento das datas do IPC; outra questão que complementa o r encontrado, reside na classificação quanto à precipitação. $\mathrm{O}$ valor encontrado na Tabela 5 para a estação MG3 relacionandoo com o veranico B, leva a crer que $r=0,76$ destacado na Tabela 6, para o mesmo veranico, esteja mais relacionado ao IPC que à quantidade de precipitação. O fato da estação MG1 ser classificada como seca, embora não apresente valor significativo, indica que a estiagem ocasionada pelo El Niño é, possivelmente, devida a veranicos com duração superior a 15 dias, conforme se observa na Figura 6B.

\section{CONCLUSÕES}

1. Em eventos El Niño, o IPC tende a tardar no centro, norte e nordeste de Minas Gerais.

2. Durante o El Niño ocorre irregularidade na distribuição de chuvas, visto que estas tendem a ficar abaixo da média na metade nordeste, enquanto se dá o oposto na metade sudoeste do Estado.

3. Os eventos de 1982/83 e 1997/98 foram os de maior influência em algumas regiões do Estado. O primeiro ocasionou anomalias acima da média, principalmente a sudoeste de Minas Gerais, enquanto o outro originou chuvas abaixo da média, em especial a nordeste do Estado.

4. As estiagens, ocasionadas pelo fenômeno climático no norte-nordeste de Minas Gerais, são devidas a períodos superiores a 15 dias e, no sul-sudoeste, aos veranicos com duração de três a seis dias.

\section{AGRADECIMENTOS}

Os autores agradecem aos senhores Elton Motta Barbosa e Júlio César Ferreira de Mello Júnior, pelo auxílio na codificação dos dados e pela elaboração do algorítimo de cálculo da ocorrência de veranicos. 


\section{LITERATURA CITADA}

Alves, J.M.B.; Repelli, C.A. A variabilidade pluviométrica no setor norte do nordeste e os eventos El Niño-Oscilação Sul (ENOS). Revista Brasileira de Meteorologia, São Paulo, v.7, n.2, p.83-92, 1992.

Aspiazu, C.; Ribeiro, G.A.; Vianello, R.L. Análise dos componentes principais aplicados na classificação climática do Estado de Minas Gerais. Teste metodológico. Revista Árvore, Viçosa, v.14, n.1, p.1-15, 1990.

Assad, E.D.; Sano, E.E. Sistema de informações geográficas Aplicações na agricultura. 2.ed. Brasília: EMBRAPA-CPAC, 1998. 434p.

Carmona, L.de C.; Berlato, M.A. El Niño e La Niña e o rendimento do arroz irrigado no Estado do Rio Grande do Sul. Revista Brasileira de Agrometeorologia, Santa Maria, v.10, n.1, p.147$152,2002$.

Castro Neto, P.; Vilella, E.A. Veranico: um problema de seca no período chuvoso. Informe Agropecuário, Belo Horizonte, v.12, n.138, p.59-62, 1986.

Chatfield, C. Wet and dry spells. Monthly Weather Review, Boston, v.21, n.3, p.308-310, 1966.

Fedorova, N.; Carvalho, M.H. de; Souza, R. de S. e. Processos sinóticos em anos de La Niña e El Niño. Parte II: Zonas Frontais. Revista Brasileira de Meteorologia, Rio de Janeiro, v.15, n.2, p.57-72, 2000.

Fontana, D.C.; Berlato, M.A. Relação entre El Niño-Oscilação Sul (ENOS), precipitação e rendimento de milho no Estado do Rio Grande do Sul. Pesquisa Agropecuária Brasileira, Brasilia, v.31, n.1, p.39-46, 1996.

Grimm, A.M.; Ferraz, S.E.T. Sudeste do Brasil: uma região de transição no impacto de eventos extremos da Oscilação Sul. Parte I: El Niño. In: Congresso Brasileiro de Meteorologia, 10, 1998, Brasília. Anais... Brasília: SBMET, 1998. CD-Rom
Grimm, A.M.; Ferraz, S.E.T.; Gomes, J. Precipitation anomalies in Southern Brazil associated with El Niño and La Niña events. Journal of Climate, Boston, v.11, n.1, p.2863-2880, 1998.

Grimm, A.M.; Natori, A.A. Relação entre a variabilidade interanual e interdecadal da chuva no Sudeste da América do Sul e da Temperatura da Superfície do Mar nos oceanos Atlântico e Pacífico. In: Congresso Brasileiro de Meteorologia, 12, 2002, Foz do Iguaçu. Anais...Foz do Iguaçu: SBMET, 2002. CD-Rom.

Kane, R.P. Limited effectiveness of El Niños in causing droughts in NE Brazil and the prominent role of Atlantic parameters. Brazilian Journal of Geophysics, Rio de Janeiro, v.19, n.2, p.231-236, 2001.

Luchiari, Jr. A.; Resende, M.; Ritchey, K.D.; Freitas Jr., E.; Souza, P.M.I. Manejo do solo e aproveitamento de água. In: Goedert, W.J. Solo dos cerrados. Planaltina: EMBRAPACPAC, 1986. p.285-322.

Oladipo, E.O. A comparative performance analysis of the three meteorological drought indexes. Journal of Climatology, Reading, v.5, n.6, p.654-655, 1985

Paiva, C.M. Determinação das datas de início e fim da estação chuvosa e da ocorrência de veranicos na Bacia do Rio Doce. Viçosa: UFV, 1997. 65p. Dissertação Mestrado

Puchalski, L.A. Efeitos associados ao fenômeno El Niño e La Niña na temperatura média, precipitação pluvial e déficit hídrico no estado do Rio Grande do Sul. Porto Alegre: UFRGS, 2000, 100p. Dissertação Mestrado

Quadros, M.F.L. Estudo de episódios de Zonas de Convergência do Atlântico Sul (ZCAS) sobre a América do Sul. São José dos Campos: INPE, 1993. 97p. Dissertação Mestrado

Silva, J. de F. da El Niño, o fenômeno climático do século. 1.ed. Brasília: Thesaurus Editora, 2000. 139p.

Silva, M.M.P.; Oliveira, N.F.; Cavalcanti, N.B. Probabilidade de ocorrência de dias secos e chuvosos. Boletim Técnico do Instituto Nacional de Meteorologia, Brasília, v.20, n.146, p.5190, 1981. 